International Journal of Methods in Psychiatric Research

Int. J. Methods Psychiatr. Res. 17(1): 35-44 (2008)

Published online in Wiley InterScience

(www.interscience.wiley.com) DOI: 10.1002/mpr.237

\title{
Psychometric properties of the Chinese version of the Swanson, Nolan, and Pelham, version IV scale - parent form
}

\author{
SUSAN SHUR-FEN GAU, ${ }^{1,2}$ CHI-YUNG SHANG, ${ }^{3}$ SHIH-KAI LIU, ${ }^{4}$ CHIEN-HO LIN, ${ }^{5}$ \\ JAMES M. SWANSON, ${ }^{6}$ YU-CHIH LIU, ${ }^{7}$ CHANG-LING TU ${ }^{1}$
}

1 Department of Psychiatry, National Taiwan University Hospital and College of Medicine, Taipei, Taiwan

2 Division of Mental Health and Substance Abuse Research, National Health Research Institute, Taiwan

3 Department of Psychiatry, Yun Lin Branch, National Taiwan University Hospital, Taipei, Taiwan

4 Department of Child and Adolescent Psychiatry, Taoyuan Mental Hospital, Department of Health, Executive Yuan, Tao-Yuan, Taiwan

5 Department of Psychiatry, Chimei Medical Center, Tainan, Taiwan

6 University of California at Irvine, Child Development Center, Irvine, CA, USA

7 Department of Psychiatry, Buddhist Dalin Tzu Chi General Hospital, Chia-Yi, Taiwan

\begin{abstract}
This study aimed to establish the psychometric properties of parent ratings on the Chinese version of the Swanson, Nolan, and Pelham IV scale (SNAP-IV) in a school-based sample of 3534 students in grades 1 to 8 from two cities and two suburbs in Taiwan and 189 children diagnosed with attention deficit/hyperactivity disorder (ADHD) (aged 6 to 15) consecutively recruited from a medical center in Taipei. Parents completed the Chinese versions of the SNAP-IV, Strengths and Difficulties Questionnaire, and Child Behavior Checklist. The Chinese SNAP-IV demonstrated similar three factor structure (Inattention, Hyperactivity/Impulsivity, and Oppositional) as its English version, and satisfactory test-retest reliability (intraclass correlation $=0.59 \sim 0.72$ ), internal consistency (alpha $=0.88 \sim 0.90)$, concurrent validity (Pearson correlations $=0.56 \sim 0.72$ ), and discriminant validity. Boys scored higher than girls across the eight school grade levels. The SNAP-IV clearly distinguished children with ADHD from school-based participants. Comorbidity with oppositional defiant disorder/conduct disorder predicted higher SNAP-IV scores among children with ADHD. Our findings suggest that the Chinese SNAP-IV is a reliable and valid instrument for rating ADHD-related symptoms in both clinical and community settings in Taiwan. Copyright (C) 2008 John Wiley $\mathcal{E}$ Sons, Ltd.
\end{abstract}

Key words: SNAP-IV, parent report, Chinese version, reliability, validity, ADHD

\section{Introduction}

Attention deficit/hyperactivity disorder (ADHD), a common and impairing childhood neuropsychiatric disorder, affects $5-10 \%$ of children and adolescents in Western countries (e.g. Faraone et al., 2003) and 7.5\% in Taiwan (Gau et al., 2005). ADHD accounts for $30 \%$ to $50 \%$ of child referrals to mental health services, and results in substantial impairment in peer, family, and academic function (The MTA Cooperative Group, 1999). Since the measurement of symptoms relies heavily on parent's reports (Jensen et al., 1999), it is crucial to prepare an internationally comparable and standardized parent-reported rating scale with good psychometric properties to screen for, assist in diagnosis of, and evaluate treatment effect of $\mathrm{ADHD}$ in Taiwan. 
Among the rating scales for ADHD symptoms, we prepared the Chinese version of the Swanson, Nolan, and Pelham rating scale version IV (SNAP-IV) for the use in clinical, research, and school settings. The SNAP (Swanson, 1992; Swanson et al., 2001; Swanson et al., 1983), different from many other behavioral rating scales, such as the Conners' Parent Rating Scale (CPRS: Conners et al., 1998) and the Child Behavior Checklist (CBCL: Achenbach, 1991), directly employs the core symptoms defined by the latest edition of the Diagnostic and Statistical Manual of Mental Disorders (DSMIV: American Psychiatric Association, 1994). Thus, it parallels the other procedures that a clinician employs in clinical practice, such as diagnostic interviews (Collett et al., 2003).

The original SNAP-IV (43 items) was shortened to 26-items for the use in the assessment batteries of the National Institute of Mental Health (NIMH) Collaborative Multisite Multimodal Treatment Study for ADHD (MTA) (The MTA Cooperative Group, 1999). It consists of the DSM-IV symptoms for the inattention (IA, Item 1-9) and the hyperactivity/impulsivity (HI, Item 10-18) of the criteria for ADHD, and the oppositional (OP) symptoms (Item 19-26) of the criteria for oppositional defiant disorder (ODD). Each item is rated on a four-point rating scale $(\mathrm{O}=$ 'not at all', $2=$ 'just a little', 3 = 'quite a bit', and 4 = 'very much'). Among the many assessment batteries in the MTA study, the three subscales of the SNAP-IV from two sources (parents and teachers) proved to be the most sensitive for documenting significant treatment group differences in the primary analyses (The MTA Cooperative Group, 1999).

In addition to the MTA study, the SNAP has been used in several clinical trials to assess the efficacy of treatment for ADHD (Abikoff et al., 2005; Correia Filho et al., 2005; Sunohara et al., 1999; Steele et al., 2006; Swanson et al., 1983; Wigal et al., 2004) and few crosssectional studies to screen for ADHD (Swanson, 1992; Swanson et al., 1999) in the Western populations.

Regarding psychometric properties of the SNAP rating scale, the SNAP-R, based on the DSM-III-R, has demonstrated a sensitivity and specificity in excess of 94\% for ADHD diagnosis (Zolotor et al., 2004) and the SNAP-IV appears to own a good internal consistency (Correia Filho et al., 2005). However, despite its frequent uses in several studies, its psychometric properties have not been adequately evaluated so far but need to be examined thoroughly.
Due to the use of the SNAP limited in the Western population, it is vitally important to evaluate its latest version (SNAP-IV) and its relative study results among different ethnic groups (Hoza et al., 2000). To our knowledge, this is the first study to examine the SNAPIV psychometric properties, including establishment of norms, reliability, and validity in a non-Western population.

\section{Subjects and methods}

\section{School-based sample}

A school-based sample of 3534 first to eighth graders was recruited from four areas: Taipei City, Taoyuan County, Tainan City and Chiayi County. The first two represent the metropolitan and suburban part of northern Taiwan and the last two represent the city and suburban parts of southern Taiwan, respectively. In April 2005, we randomly selected one or two primary and junior high schools according to the school sizes among the schools with principals' consent to this study in each site. Two to three classes from each grade level (grade 1 to 8 ) were randomly selected according to the estimated 100 to 120 students at each school grade level in each study site. In total, 116 classes and 3534 participants (1822 boys and 1712 girls) and their parents consented to this study and were, therefore, included in the final sample. About half of fathers and mothers were senior high graduates $(50.9 \%, 57.6 \%)$ and one-quarter were college graduates or above $(28.9 \%$, $21.0 \%)$, respectively. There were $35,25,24,32$ classes and 984 (27.8\%), 809 (22.9\%), 795 (22.5\%), 946 (26.8\%) students in Taipei, Taoyuan, Chiayi, and Tainan, respectively. The average participation rate was $92 \%$, $92 \%, 96 \%, 94 \%$, and $86 \%$ out of total $1078,849,858$, 1114 eligible students in each of four areas orderly.

\section{Clinical-based sample}

We recruited 189 children aged 6-15 (male, 86.2\%) consecutively, who had their first or regular visit to the Children's Mental Health Center, National Taiwan University Hospital (NTUH), between June 2005 and September 2005. All of them were diagnosed with ADHD and were not comorbid with pervasive developmental disorder and/or mental retardation or other psychiatric disorders with the exception of ODD (38, $20 \%)$, conduct disorder (CD: 20, 10.6\%) and tics (9, 4.8\%). Of them, 126 (66.7\%), 52 (27.5\%), and 11 (5.8\%) were diagnosed with combined type, predominantly 
inattentive type, and predominantly hyperactiveimpulsive type, respectively.

The DSM-IV diagnosis of ADHD and other psychiatric disorders were made based on the clinical diagnoses by the first author (SS Gau) and also confirmed by the psychiatric interviews using the Chinese Kiddieschedule for Affective Disorders and Schizophrenia Epidemiology version (K-SADS-E) (e.g. Gau et al., 2005) before or during the study period. The Chinese K-SADS-E, a reliable and valid instrument, has been used extensively in a variety of studies regarding childhood mental disorders in Taiwan (e.g. Gau et al., 2005).

\section{Instruments}

The instruments included the 26-item Chinese SNAPIV based on parental rating, the Strengths and Difficulties Questionnaire (SDQ), and the CBCL.

Strengths and Difficulties Questionnaires (SDQ)

The SDQ, a 25-item behavioral screening questionnaire, is designed to assess a broader area of different behavioral aspects of children and adolescents. Each item is rated on a three-point Likert scale (not true, somewhat true, and certainly true) (Goodman, 1999). The psychometric properties of the parental version of the Chinese SDQ were conducted by Gau SS with the permission of Goodman, in which four subscales were identified: Conduct Problem, Inattention/Hyperactivity, Prosocial, and Internalizing. The Conduct Problem and Inattention/Hyperactivity subscales were used to validate the SNAP-IV for this study. The Chinese SDQ has demonstrated good test-retest reliability (intraclass correlations, ICC) and moderate internal consistency (Cornbach's alpha, $\alpha$ ) for the Conduct Problem subscale (ICC $=0.71, \alpha=0.66$ ) and the Inattention/ Hyperactivity subscale (ICC $=0.77, \alpha=0.72$ ).

\section{Child Behavior Checklist (CBCL)}

The CBCL is a parental report concerning their children aged 4-18. Two broad-band syndromes and eight narrow-band syndromes are derived from the 118 emotional and behavioral items (Achenbach, 1991). The Chinese CBCL, a reliable and valid instrument, has been widely used to measure behavioral syndromes in Taiwanese child and adolescent populations (Shang et al., 2006; Yang et al., 2001). In this study, four syndromes (Aggressive Behavior, Delinquent Behavior, Attention Problems, and Externalizing Behavior) were used to validate the Chinese SNAP-IV. The alpha coefficients for the four subscales ranged from 0.69 to 0.90 in this study.

\section{Cutoff criteria for screening for potential ADHD}

Three approaches were employed to identify potential cases of ADHD based on the scores of the Chinese SNAP-IV. The first two approaches include the employment of the top 5\% scores (Swanson et al., 1999) and the $t$-score greater than 70 [two standard deviations (SD) greater than mean] (Swanson, 1992) as the cut-off point to define the presence of extreme IA or HI. The $t$-score was defined by multiplying the $z$-score by 10 and adding 50 with a mean of 50 and a SD of $10(t$-score $=$ $z$-score $\times 10+50$ ). The third approach was based on the symptom-count criterion from full diagnostic criteria stated in the DSM-IV. A score of 2 (quite a bit) or 3 (very much) was coded as the symptomatic presence of this behavior and otherwise as absence (Steele et al., 2006; Swanson et al., 2001). According to the DSM-IV, we defined presence of the IA syndrome if at least six of the nine IA items and presence of the HI syndrome if at least six of the nine HI items. The three subtypes of ADHD symptoms were assigned based on DSM-IV diagnostic criteria for ADHD subtypes.

\section{Procedures}

The Chinese SNAP-IV was prepared with culturerelevant colloquial expressions and two-way translation by SS Gau and colleagues after granted with the permission of Swanson to ascertain the linguistic and content validity of this scale. The Research Ethics Committee (IRB) of the NTUH approved this study prior to multistage sampling in May 2005. Written informed consents were obtained from the parents of both the schoolbased subjects and clinical subjects after an explanation of the purpose and procedure of the study along with the reassurance of confidentiality. The parents of the school-based subjects completed the questionnaires at home. Of the 3534 participants, 221 subjects were randomly selected for the test-retest reliability study at a four-week interval (participation rate $=100 \%$ ). Mothers of clinical subjects completed the rating scales either during their visits at the NTUH or at home.

\section{Statistical analysis}

Data analyses were performed using SAS 9.1 (SAS Institute Inc., Cary, NC, USA). Pearson correlations $\left(\gamma_{p}\right)$ and ICC were calculated for the test-retest 
reliability, and Cronbach's alpha $(\alpha)$ was calculated for the internal consistency of three subscales of the Chinese SNAP-IV. A linear mixed model was employed to compute the ICC for assessing the stability of two ratings within the same subject by calculating between subject variability over total variance, which consists of between-subject and within-subject variability (Muller and Buttner, 1994). A paired t-test was further employed to test the difference of the repeated measures. The concurrent validity was tested by the correlations between the subscales of the Chinese SNAP-IV, and SDQ and CBCL.

A linear mixed model with both fixed and random effects was also used to address subjects nested within the same class and school for the multi-stage sampling of the school-based sample (Singer, 1998). The linear trend for eight school grade levels was tested for each subscale after departure from the linear trend was rejected based on the Bayesian information criterion (i.e. Schwarz's Bayesian criterion), by comparing the model that treated school grade level as a categorical variable with the model that treated the eight school grade levels as a dimensional variable.

Since the SNAP-IV is based on the DSM-IV symptom criteria of ADHD and ODD, we did not perform exploratory factor analysis but confirmatory factory analysis (three-factor model) using variancecovariance matrix of the ratings of all 26 items of the Chinese SNAP-IV. To evaluate discriminant validity, analysis of covariance was used to compare the mean scores and the $t$-scores of the subscales of the SNAP-IV between the 189 clinical subjects with ADHD and 395 participants without ADHD randomly selected from the school-based sample according to the sex and age structures of the ADHD group. The mean score of the each subscale in the school-based sample of this study was used to calculate the $t$-score for clinical subjects. Cohen's $d$ was used to compute the effect size (standardized difference between the two means) for the ADHD and non-ADHD groups (Cohen, 1988). We also compared the $t$-scores of the three scales of the SNAP-IV among ADHD children with ODD/CD, ADHD children without comorbid with ODD/CD, and normal controls. Bonferroni method was used to adjust $p$ values for the comparisons among the three groups.

\section{Results}

Test-retest reliability and internal consistency

The Chinese SNAP-IV demonstrated good test-retest reliability $\left(\gamma_{p}=0.61 \sim 0.73\right.$ and ICC $\left.=0.59 \sim 0.72\right)$ and high internal consistency (all $\alpha \geq 0.88$ ) for three subscales (Table 1). Although there was significant difference between the two measurements in the $\mathrm{HI}$ and $\mathrm{OP}$, all the 95\% confidence intervals for the difference included zero suggesting no difference between the two measurements.

Table 1. Test-retest reliability and internal consistency of the Chinese SNAP-IV

\begin{tabular}{|c|c|c|c|c|c|c|c|c|}
\hline \multirow[t]{2}{*}{ Subscale } & \multicolumn{7}{|c|}{ Test-retest reliability $(n=221)$} & \multirow{2}{*}{$\begin{array}{c}\begin{array}{c}\text { Internal } \\
\text { consistency } \\
(n=3534)\end{array} \\
\text { Cronbach } \alpha\end{array}$} \\
\hline & $\gamma$ & ICC & $\begin{array}{c}1 \text { st } \\
\text { Mean } \pm \text { SD }\end{array}$ & $\begin{array}{c}\text { 2nd } \\
\text { Mean } \pm \text { SD }\end{array}$ & $\begin{array}{l}\text { Difference Mean } \\
\quad(95 \% \mathrm{CI})\end{array}$ & $\begin{array}{l}t \text { Value } \\
(\mathrm{df}=1)\end{array}$ & $p$ Value & \\
\hline Inattention & $0.73 *$ & 0.72 & $0.72 \pm 0.55$ & $0.69 \pm 0.51$ & $-0.03(-0.42,0.36)$ & -1.15 & 0.251 & 0.88 \\
\hline $\begin{array}{l}\text { Hyperactivity/ } \\
\text { Impulsivity }\end{array}$ & $0.68 *$ & 0.67 & $0.48 \pm 0.51$ & $0.42 \pm 0.47$ & $-0.07(-0.46,0.32)$ & -1.59 & 0.012 & 0.88 \\
\hline Oppositional & $0.61^{*}$ & 0.59 & $0.67 \pm 0.50$ & $0.55 \pm 0.47$ & $-0.11(-0.55,0.33)$ & -3.82 & 0.000 & 0.90 \\
\hline
\end{tabular}

SNAP-IV, Swanson, Nolan, and Pelham, version IV; $\gamma$, Pearson correlation; ICC, intraclass correlation; CI, confidence interval.

$* p<0.0001$. 


\section{Confirmatory Factor Analysis}

Estimation of model fit of Confirmatory Factor Analysis using three-factor model (Items 1-9 for IA, Items 10-18 for HI, Items 19-26 for OP) was based on maximum likelihood method. The chi-square statistics was not computed as an index of fit as it was affected substantially by the huge sample size of this study. Instead, the following indices of fit, less affected by sample size, were computed: goodness-of-fit index (0.87), goodness-of-fit index adjusted for degree of freedom (df) (0.85), and root mean square residual (0.02), and root mean squared error approximation coefficient (0.07). The indices of model fit demonstrated that the three-factor model fit our data well.

\section{Concurrent validity}

The IA subscale was highly correlated with the corresponding subscale of the SDQ and CBCL (Table 2). The HI and OP subscales were highly correlated with the Aggressive Behaviors and Externalizing Behaviors of the CBCL (Table 2).

\section{Gender and age differences}

Table 3 presents the mean score and SD of the three subscales of the SNAP-IV by gender and school grade levels. Boys scored significantly higher in the IA and $\mathrm{HI}$ subscales across the eight age groups and in the OP subscale only at grade 2 and grade 4 . The HI symptom ratings declined with age but the IA and OP symptoms did not (Table 3). There was no interaction between gender and the eight school grade levels on the severity of symptoms.

\section{Discriminant validity}

Table 4 lists the mean $t$-scores and SD of the subscales of the SNAP-IV among three groups: ADHD with ODD/CD, ADHD alone, and school controls (Table 4). Children with ADHD alone had higher SNAP-IV scores than the school controls (Table 4) with the large effect size, defined by Cohen's $d$ (Cohen, 1988), ranging from 1.46 for the IA subscale, 1.15 for the HI subscale, to 0.72 for the OP subscale. Compared to children with ADHD alone, children with ADHD comorbid with ODD/CD significantly scored higher on the IA (Cohen's $d=0.69$ ), HI (Cohen's $d=0.66$ ), and OP symptoms (Cohen's $d=1.44$ ).

By using the three approaches of the SNAP-IV to screen for potential cases of ADHD (Table 5), we found that clinical subjects with ADHD who were currently non-medicated (68.7 75.1\%) had highest rates reaching the cut-off criteria for potential cases of ADHD, followed by clinical subjects with ADHD who were currently medicated (56.3 57.6\%), and school-based subjects the least (7.1 7.2\%).

\section{Discussion}

In Taiwan, the increased public awareness of ADHD and similar prevalence rate of DSM-IV ADHD to

Table 2. Correlations between the subscales of the Chinese SNAP-IV, SDQ, and CBCL*

\begin{tabular}{|c|c|c|c|c|}
\hline \multirow[t]{2}{*}{ Scale } & \multicolumn{3}{|c|}{ Chinese SNAP-IV parent $(N=3534)$} & \multirow{2}{*}{$\frac{\text { Internal consistency }}{\text { Cronbach } \alpha}$} \\
\hline & Inattention & Hyperactivity & Oppositional & \\
\hline \multicolumn{5}{|l|}{$\operatorname{SDQ}(n=3532)$} \\
\hline Conduct problems & 0.54 & 0.58 & 0.61 & 0.66 \\
\hline Inattention/Hyperactivity & 0.67 & 0.56 & 0.42 & 0.72 \\
\hline \multicolumn{5}{|l|}{$\operatorname{CBCL}(n=3528)$} \\
\hline Aggressive behaviors & 0.57 & 0.68 & 0.72 & 0.90 \\
\hline Delinquent behaviors & 0.51 & 0.57 & 0.56 & 0.83 \\
\hline Attention problems & 0.70 & 0.63 & 0.55 & 0.83 \\
\hline Externalizing behaviors & 0.58 & 0.67 & 0.70 & 0.93 \\
\hline
\end{tabular}

SNAP-IV, Swanson, Nolan, and Pelham, version IV; SDQ, Strengths and Difficulties Questionnaire; CBCL, Child Behavior Checklist.

*All correlations are statistically significant at $p<0.0001$ level. 


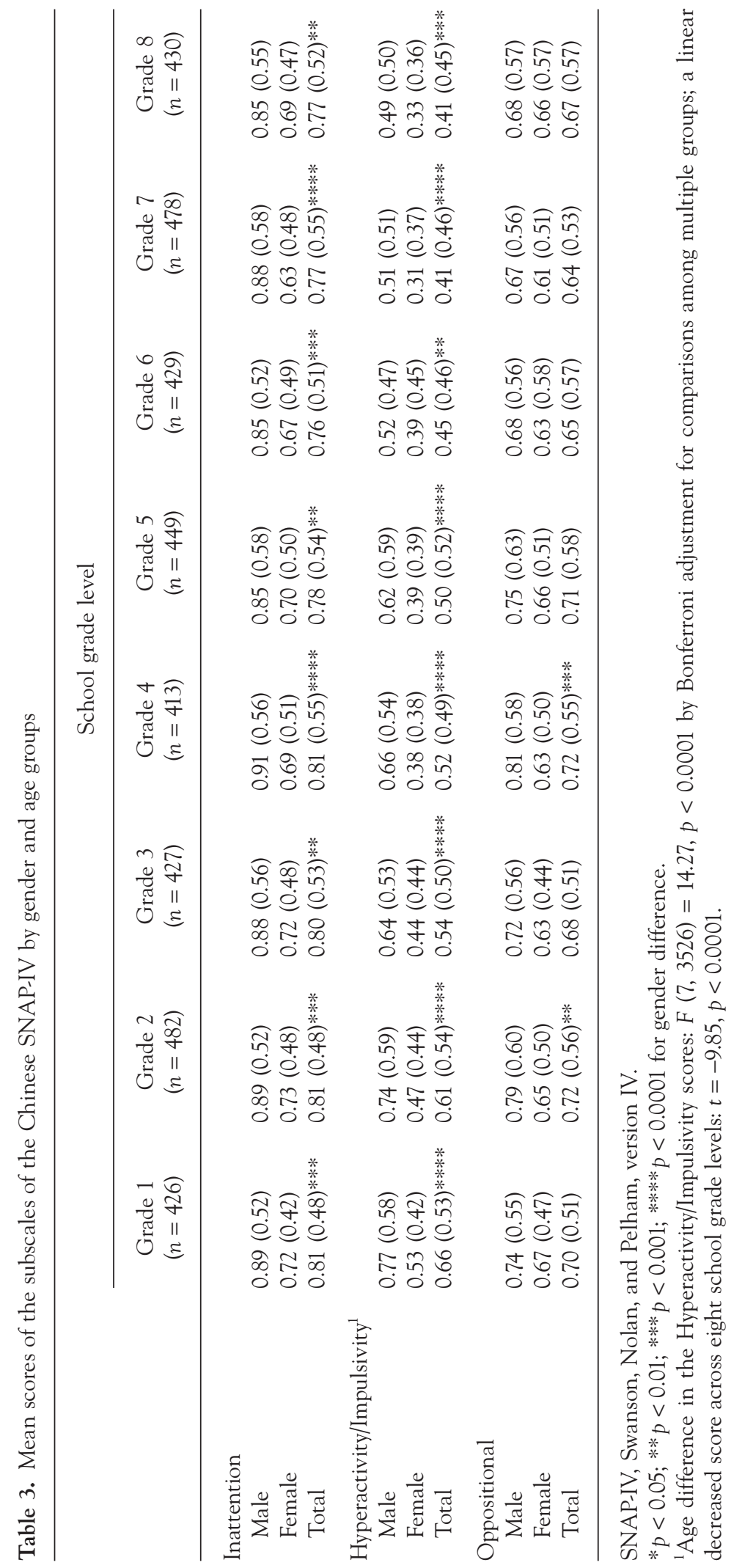


Table 4. The $t$-scores of the Chinese SNAP-IV by ADHD children with ODD/CD, ADHD children without ODD/CD, and normal controls

\begin{tabular}{|c|c|c|c|c|}
\hline Mean $t$-score (SD) & $\begin{array}{l}\text { ADHD with ODD/CD } \\
\qquad(N=51)\end{array}$ & ADHD only $(N=138)$ & Controls $(N=395)$ & Comparisons ${ }^{1}$ \\
\hline Inattention & $75.4(11.1)$ & $67.3(12.5)$ & $50.4(10.5)$ & $\begin{array}{c}F_{(4,579)}=198.11 \\
p<0.0001\end{array}$ \\
\hline Hyperactivity/Impulsivity & $74.5(15.4)$ & $65.1(13.1)$ & $51.1(11.1)$ & $\begin{array}{c}F_{(4,579)}=133.93 \\
p<0.0001\end{array}$ \\
\hline Oppositional & $75.1(12.8)$ & $57.9(11.1)$ & $50.1(10.7)$ & $\begin{array}{c}F_{(4,579)}=128.37 \\
p<0.0001\end{array}$ \\
\hline
\end{tabular}

SNAP-IV, Swanson, Nolan, and Pelham, version IV; ADHD, Attention deficit/hyperactivity disorder; ODD, oppositional defiant disorder; $\mathrm{CD}$, conduct disorder.

${ }^{1}$ Bonferroni method to adjust the $p$ value for multiple comparisons among the three groups. All comparisons are: ADHD with ODD/CD $>$ Controls, ADHD only $>$ Controls, and ADHD with ODD/CD $>$ ADHD only at adjusted $p$ value $<0.05$.

Table 5. Rates of potential cases of ADHD defined by the Chinese SNAP-IV scores for community and clinical subjects

\begin{tabular}{|c|c|c|c|c|c|}
\hline & \multirow[t]{2}{*}{$N(\%)$} & \multirow{2}{*}{$\begin{array}{l}\text { Community subjects } \\
\qquad(n=3534)\end{array}$} & \multicolumn{3}{|c|}{ Clinical subjects } \\
\hline & & & $\begin{array}{l}\text { Non-medicated } \\
\quad(n=32)\end{array}$ & $\begin{array}{c}\text { Medicated } \\
(n=153)\end{array}$ & $\begin{array}{c}\text { Total } \\
(n=185)\end{array}$ \\
\hline \multirow[t]{4}{*}{$95 \%$ of mean score } & ADHD & $251(7.1)$ & $22(68.7)$ & $84(56.3)$ & $108(58.4)$ \\
\hline & Combined & $163(4.6)$ & $17(53.1)$ & $78(51.0)$ & $95(51.4)$ \\
\hline & Inattention & $52(1.5)$ & $4(12.5)$ & $8(5.3)$ & $12(6.5)$ \\
\hline & Hyperactivity/Impulsivity & $36(1.0)$ & $1(3.1)$ & $0(0.0)$ & $1(0.5)$ \\
\hline \multirow[t]{4}{*}{ DSM-IV criteria } & ADHD & $256(7.2)$ & $24(75.1)$ & $88(57.6)$ & $112(60.5)$ \\
\hline & Combined & $146(4.1)$ & $8(25.0)$ & $42(27.5)$ & $50(27.0)$ \\
\hline & Inattention & $52(1.5)$ & $14(43.8)$ & $33(21.6)$ & $47(25.4)$ \\
\hline & Hyperactivity/Impulsivity & $58(1.6)$ & $2(6.3)$ & $13(8.5)$ & $15(8.1)$ \\
\hline \multirow{4}{*}{$\begin{array}{l}t-S c o r e \text { greater } \\
\text { than } 70\end{array}$} & ADHD & $274(7.7)$ & $23(71.9)$ & $106(57.0)$ & $110(59.5)$ \\
\hline & Combined & $160(4.5)$ & $17(53.1)$ & $94(50.5)$ & $95(51.4)$ \\
\hline & Inattention & $54(1.5)$ & $4(12.5)$ & $10(5.4)$ & $12(6.5)$ \\
\hline & Hyperactivity/Impulsivity & $60(1.7)$ & $2(6.3)$ & $2(1.1)$ & $3(1.6)$ \\
\hline
\end{tabular}

SNAP-IV, Swanson, Nolan, and Pelham, version IV; ADHD, Attention deficit/hyperactivity disorder.

Western countries (Gau et al., 2005) highlight the need for an instrument to measure ADHD symptoms in a comparable fashion as in Western cultures. To fulfill this need, we conducted a comprehensive evaluation of the psychometric properties of the Chinese SNAP-IV in both school-based and clinic-based samples. Our findings showed that the Chinese SNAP-IV demonstrated similar factor structure to its English version, and satisfactory reliability and validity. In addition to distinguishing ADHD children from school-based children, the SNAP-IV also demonstrated the ability to discriminate ADHD children with comorbid ODD/CD from children with ADHD alone.

Reliability of the Chinese SNAP-IV

Our findings showed that the three subscales of the Chinese SNAP-IV were stable over time, and had high internal consistency, suggesting it may be more stable 
than the English version (Correia Filho et al., 2005). The high stability suggests that evidence of strong change in the scores of the SNAP-IV in clinical studies could safely be interpreted as due to treatment effects rather than to random inter-temporal fluctuations in scale scores.

\section{Gender differences}

Similar to most previous studies of ADHD-related rating scales (e.g. Fantuzzo et al., 2001; Koot et al., 1997), but not all (Al-Awad and Sonuga-Barke, 2002; Kumar and Steer, 2003), boys scored higher than girls in the two ADHD subscales. This finding is crossculturally valid (Crijnen et al., 1999), indicating that the gender difference cannot be explained by reporter's bias or the employment of different instruments. These findings support the argument that we should consider gender effect in diagnosing ADHD (Gomez et al., 1999; Pelham et al., 1992).

\section{Age effects}

Consistent with previous studies, our findings lent evidence to support a decline in hyperactivity with age (e.g. Conners et al., 1998; Gau et al., 2006) and no age difference in IA (e.g. Gau et al., 2006; Kumar and Steer, 2003). These findings imply that the degree of ageinappropriate IA might not change but severity of hyperactivity symptoms might decrease from childhood to adolescence in the general population (Gau et al., 2006). Lack of longitudinally follow-up information limits our ability to test the hypothesis that IA persists and hyperactivity decreases from childhood to adolescence (e.g. Biederman et al., 2000).

\section{Validity of the Chinese SNAP-IV}

Two well-known measures (CBCL and SDQ) of behavioral problems were used to demonstrate good concurrent validity of the Chinese SNAP-IV. Moreover, the effect sizes for the comparisons of the three subscales between the ADHD and school controls were apparently large, implying that not only the IA and HI subscales but also the OP subscale clearly distinguished the clinical subjects with ADHD from their counterparts. Several reasons could explain the unique finding of ability of the OP subscale in distinguishing ADHD from non-ADHD. First, given that ODD is highly comorbid with ADHD, the correlations among these three subscales are anticipated to be high as well. Secondly, most parents in the Chinese culture expect their children to be submissive and obedient (Chao, 1994). Therefore, when an ADHD child displays certain problematic behaviors, parents might interpret them as challenging and defiant and consequently tend to score higher on the OP items.

Moreover, the discriminant validity of the SNAP-IV is also demonstrated by its ability to distinguish the comorbid condition with ODD/CD among children with ADHD suggesting the association between presence of $\mathrm{ODD} / \mathrm{CD}$ and increased severity of the core symptoms of ADHD.

Another approach to establish the discriminant validity of the SNAP-IV is to compare the rates of subjects with apparent ADHD symptoms among clinical subjects with ADHD currently treated and not treated with medication, and school-based controls based on the three scoring methods proposed by Swanson (Swanson, 1992; Swanson et al., 1999; Swanson et al., 2001). Under anticipation, the three approaches clearly distinguish ADHD children without medication treatment, from ADHD children with medication treatment, and from school controls. The overall prevalence rate of potential cases of ADHD in the community sample was close to the figures of recent studies in Australia (Graetz et al., 2001) with the Diagnostic Interview Schedule for Children, in Brazil (Rohde et al., 1999) with the DSM-IV symptom items, and in Taiwan (Gau et al., 2005) with the Chinese KSADS-E interviews. In addition, consistent with the DSM-IV field trial (Gomez et al., 1999), this study also found the Combined type to be the most prevalent subtype. In sum, these results indicates that SNAP-IV is a valid screening instrument for identifying potential cases of ADHD and can facilitate the diagnosis process when the formal psychiatric interview is not feasible.

\section{Limitations and strengths}

The strengths of this study include a large-scale nonreferred school-based sample with a wide age range of children from 6 to 15 years old and a satisfactory response rate, recruitment of both community and clinic samples, first study to conduct Confirmatory Factor Analysis of the SNAP-IV, and reliable and valid standardized instruments for the assessments of the concurrent validity of the Chinese SNAP-IV. This study is limited by questionable external validity and no psychiatric interview conducted in community subjects. Although this study recruited subjects from two cities and two suburbs in Taiwan, its external validity 
in broader Taiwanese or Chinese populations needs to be examined. Without psychiatric diagnosis among school-based subjects, the appropriate cut-off points of the Chinese SNAP-IV cannot be identified for diagnosis of ADHD.

\section{Implications}

Our findings of similar factor structures and high internal consistency of the three subscales of the Chinese SNAP-IV suggest that the symptom manifestation of ADHD and ODD in Taiwanese children and adolescents are not culturally different from American children and adolescents. Our results on test-retest stability and validity suggest that the Chinese SNAP-IV is a reliable and valid instrument to assess symptoms of ADHD and ODD for screening and assisting diagnosis for ADHD and evaluating of treatment effect.

The SNAP-IV is especially attractive because of its brevity, ease of administration, and modification from the DSM-IV criteria. It can supplement other disciplines other than psychiatry, such as pediatrics, to identify potential cases of ADHD when a clinical psychiatric interview is not available. Moreover, it can be used along with the Chinese K-SADS-E (Gau et al., 2005) in epidemiological studies concerning the prevalence and symptoms change of ADHD in a large and varied population in Taiwan. As a result, early identification is possible and attempts of prevention can be provided. However, it is important to note that no rating scale alone will provide sufficient evidence to reliably establish the diagnosis of ADHD. Clinical interviews, information from several sources (such as parent and teacher reports), and when possible, objective supporting evidence, are crucial in making diagnosis of ADHD.

In conclusion, our results show that the Chinese version of the parent SNAP-IV has satisfactory psychometric properties consistent with those results with Western samples and the cross-cultural validity as well. The current study has contributed to the development of the internationally recognized instruments for clinical and research use with ADHD population in Taiwan.

\section{Acknowledgments}

This study was supported by grants from the National Health Research Institute (NHRI-EX94-9407PC), National Taiwan University Hospital (NTUH 95-301), Department of Health, Taiwan (DOH-95-HO-9518), and Buddhist Dalin Tzu Chi General Hospital (DTCRD 94(2)-02), Taiwan.

\section{References}

Abikoff H, McGough J, Vitiello B, McCracken J, Davies M, Walkup J, Riddle M, Oatis M, Greenhill L, Skrobala A, March J, Gammon P, Robinson J, Lazell R, McMahon DJ, Ritz L. The RAASG. Sequential pharmacotherapy for children with comorbid attention-deficit/hyperactivity and anxiety disorders. J Am Acad Child Adolesc Psychiatry 2005; 44: 418-27.

Achenbach TM. Manual for the Child Behavior Checklist/ 4-18 and 1991 Profile. Burlington, VT: Department of Psychiatry, University of Vermont, 1991.

Al-Awad AM, Sonuga-Barke EJ. The application of the Conners' Rating Scales to a Sudanese sample: an analysis of parents' and teachers' ratings of childhood behaviour problems. Psychol Psychother 2002; 75: 177-87.

American Psychiatric Association. Diagnostic and statistical manual of mental disorders, 4th edition. Washington, DC: American Psychiatric Association, 1994.

Biederman J, Mick E, Faraone SV. Age-dependent decline of symptoms of attention deficit hyperactivity disorder: impact of remission definition and symptom type. Am J Psychiatry 2000; 157: 816-8.

Chao RK. Beyond parental control and authoritarian parenting style: understanding Chinese parenting through the cultural notion of training. Child Dev 1994; 65: 1111-9.

Cohen M. The revised Conners Parent Rating Scale: factor structure replication with a diversified clinical sample. J Abnorm Child Psychol 1988; 16: 187-96.

Collett BR, Ohan JL, Myers KM. Ten-year review of rating scales. V: scales assessing attention-deficit/hyperactivity disorder. J Am Acad Child Adolesc Psychiatry 2003; 42: 1015-37.

Conners CK, Sitarenios G, Parker JD, Epstein JN. The revised Conners' Parent Rating Scale (CPRS-R): factor structure, reliability, and criterion validity. J Abnorm Child Psychol 1998; 26: 257-68.

Correia Filho AG, Bodanese R, Silva TL, Alvares JP, Aman $\mathrm{M}$, Rohde LA. Comparison of risperidone and methylphenidate for reducing ADHD symptoms in children and adolescents with moderate mental retardation. J Am Acad Child Adolesc Psychiatry 2005; 44: 748-55.

Crijnen AA, Achenbach TM, Verhulst FC. Problems reported by parents of children in multiple cultures: the Child Behavior Checklist syndrome constructs. Am J Psychiatry 1999; 156: 569-74.

Fantuzzo J, Grim S, Mordell M, McDermott P, Miller L, Coolahan K. A multivariate analysis of the revised Conners' Teacher Rating Scale with low-income, urban preschool children. J Abnorm Child Psychol 2001; 29: 141-52.

Faraone SV, Sergeant J, Gillberg C, Biederman J. The worldwide prevalence of ADHD: is it an American condition? World Psychiatry 2003; 2: 104-13.

Gau SS, Chong MY, Chen TH, Cheng AT. A 3-year panel study of mental disorders among adolescents in Taiwan. Am J Psychiatry 2005; 162: 1344-50. 
Gau SS, Soong WT, Chiu YN, Tsai WC. Psychometric properties of the Chinese version of the Conners' Teacher and Parent Rating Scales - revised short form. J Atten Disord 2006; 9: 648-59.

Gomez R, Harvey J, Quick C, Scharer I, Harris G. DSM-IV $\mathrm{AD} / \mathrm{HD}$ : confirmatory factor models, prevalence, and gender and age differences based on parent and teacher ratings of Australian primary school children. J Child Psychol Psychiatry 1999; 40: 265-74.

Goodman R. The extended version of the Strengths and Difficulties Questionnaire as a guide to child psychiatric caseness and consequent burden. J Child Psychol Psychiatry 1999; 40: 791-801.

Graetz BW, Sawyer MG, Hazell PL, Arney F, Baghurst P. Validity of DSM-IV ADHD subtypes in a nationally representative sample of Australian children and adolescents. J Am Acad Child Adolesc Psychiatry 2001; 40: 1410-7.

Hoza B, Owens JS, Pelham WE, Swanson JM, Conners CK, Hinshaw SP, Arnold LE, Kraemer HC. Parent cognitions as predictors of child treatment response in attentiondeficit/hyperactivity disorder. J Abnorm Child Psychol 2000; 28: 569-83.

Jensen PS, Rubio-Stipec M, Canino G, Bird HR, Dulcan MK, Schwab-Stone ME, Lahey BB. Parent and child contributions to diagnosis of mental disorder: are both informants always necessary? J Am Acad Child Adolesc Psychiatry 1999; 38: 1569-79.

Koot HM, Van Den Oord EJ, Verhulst FC, Boomsma DI. Behavioral and emotional problems in young preschoolers: cross-cultural testing of the validity of the Child Behavior Checklist/2-3. J Abnorm Child Psychol 1997; 25: 183-96.

Kumar G, Steer RA. Factorial validity of the Conners' Parent Rating Scale-revised: short form with psychiatric outpatients. J Pers Assess 2003; 80: 252-9.

Muller R, Buttner P. A critical discussion of intraclass correlation coefficients. Stat Med 1994; 13: 2465-76.

Pelham WE Jr, Gnagy EM, Greenslade KE, Milich R. Teacher ratings of DSM-III-R symptoms for the disruptive behavior disorders [erratum appears in J Am Acad Child Adolesc Psychiatry 1992; 31(6): 1177]. J Am Acad Child Adolesc Psychiatry 1992; 31: 210-8.

Rohde LA, Biederman J, Busnello EA, Zimmermann H, Schmitz M, Martins S, Tramontina S. ADHD in a school sample of Brazilian adolescents: a study of prevalence, comorbid conditions, and impairments. J Am Acad Child Adolesc Psychiatry 1999; 38: 716-22.

Shang CY, Gau SSF, Soong WT. Association between childhood sleep problems and perinatal factors, parental mental distress and behavioral problems. J Sleep Res 2006; 15: 63-73.

Singer JD. Using SAS PROC MIXED to fit multilevel models, hierarchical models, and individual growth models. J Educ Behav Stat 1998; 23: 323-55.
Steele M, Weiss M, Swanson JM, Wang J, Prinzo RS, Binder C. A randomized, controlled, effectiveness trial of OROSmethylphenidate compared to usual care with immediaterelease methylphenidate in attention deficit-hyperactivity disorder. Can J Clin Pharmacol 2006; 13: 50-62.

Sunohara GA, Malone MA, Rovet J, Humphries T, Roberts W, Taylor MJ. Effect of methylphenidate on attention in children with attention deficit hyperactivity disorder (ADHD): ERP evidence. Neuropsychopharmacology 1999; 21: 218-28.

Swanson J, Lerner M, March J, Gresham FM. Assessment and intervention for attention-deficit/hyperactivity disorder in the schools. Lessons from the MTA study. Pediatr Clin N Am 1999; 46: 993-1009.

Swanson JM. School-based Assessments and Interventions for ADD Students. Irvine, CA: K.C. Press, 1992.

Swanson JM, Sandman CA, Deutsch C, Baren M. Methylphenidate hydrochloride given with or before breakfast: I. Behavioral, cognitive, and electrophysiologic effects. Pediatrics 1983; 72: 49-55.

Swanson JM, Kraemer HC, Hinshaw SP, Arnold LE, Conners CK, Abikoff HB, Clevenger W, Davies M, Elliott GR, Greenhill LL, Hechtman L, Hoza B, Jensen PS, March JS, Newcorn JH, Owens EB, Pelham WE, Schiller E, Severe JB, Simpson S, Vitiello B, Wells K, Wigal T, Wu $M$. Clinical relevance of the primary findings of the MTA: success rates based on severity of ADHD and ODD symptoms at the end of treatment. J Am Acad Child Adolesc Psychiatry 2001; 40: 168-79.

The MTA Cooperative Group. A 14-month randomized clinical trial of treatment strategies for attention-deficit/ hyperactivity disorder. Arch Gen Psychiatry 1999; 56: 1073-86.

Wigal S, Swanson JM, Feifel D, Sangal RB, Elia J, Casat CD, Zeldis JB, Conners CK. A double-blind, placebocontrolled trial of dexmethylphenidate hydrochloride and D,L-threo-methylphenidate hydrochloride in children with attention-deficit/ hyperactivity disorder. J Am Acad Child Adolesc Psychiatry 2004; 43: 1406-14.

Yang HJ, Chen WJ, Soong WT. Rates and patterns of comorbidity of adolescent behavioral syndromes as reported by parents and teachers in a Taiwanese nonreferred sample. J Am Acad Child Adolesc Psychiatry 2001; 40: 1045-52.

Zolotor A, Mayer J, Hill J. Clinical inquiries. Does a short symptom checklist accurately diagnose ADHD? J Fam Pract 2004; 53: 412-6.

Correspondence: Susan Shur-Fen Gau, Department of Psychiatry, National Taiwan University Hospital, No. 7, Chung-Shan South Road, Taipei, 10002, Taiwan

Telephone +886-2-23123456 ext. 6802

Fax +886-2-23812408

Email: gaushufe@ntu.edu.tw 